\title{
How useful are clinical details in blunt trauma referrals for computed tomography of the abdomen?
}

\begin{tabular}{|c|c|}
\hline $\begin{array}{l}\text { Authors: } \\
\text { Kenneth B. Bel } \\
\text { Martin Kidd } \\
\text { Richard D. Pitc }\end{array}$ & $\begin{array}{l}\text { iss-Challinor }{ }^{1} \text { (D) } \\
\operatorname{her}^{1} \text { (D) }\end{array}$ \\
\hline $\begin{array}{l}\text { Affiliations: } \\
{ }^{1} \text { Division of Ra } \\
\text { Department o } \\
\text { Imaging and C } \\
\text { Oncology, Fac } \\
\text { Medicine and } \\
\text { Sciences, Stell } \\
\text { University, Car } \\
\text { South Africa }\end{array}$ & $\begin{array}{l}\text { diodiagnosis, } \\
\text { f Medical } \\
\text { linical } \\
\text { ulty of } \\
\text { Health } \\
\text { enbosch } \\
\text { e Town, }\end{array}$ \\
\hline $\begin{array}{l}{ }^{2} \text { Centre for Sta } \\
\text { Consultation, } \\
\text { University, Ste } \\
\text { South Africa }\end{array}$ & $\begin{array}{l}\text { tistical } \\
\text { Stellenbosch } \\
\text { Ilenbosch, }\end{array}$ \\
\hline $\begin{array}{l}\text { Correspondin } \\
\text { Kenneth Bevis } \\
\text { ken.beviss@g }\end{array}$ & $\begin{array}{l}\text { author: } \\
\text { s-Challinor, } \\
\text { nail.com }\end{array}$ \\
\hline $\begin{array}{l}\text { Dates: } \\
\text { Received: } 16 \\
\text { Accepted: } 02 \\
\text { Published: } 22\end{array}$ & $\begin{array}{l}\text { ec. } 2019 \\
\text { Mar. } 2020 \\
\text { Apr. } 2020\end{array}$ \\
\hline $\begin{array}{l}\text { How to cite th } \\
\text { Beviss-Challin } \\
\text { Pitcher R. Hov } \\
\text { clinical details } \\
\text { trauma referr } \\
\text { computed ton } \\
\text { abdomen? S A } \\
\text { 2020;24(1), a1 } \\
\text { doi.org/10.41 } \\
\text { v24i1.1837 }\end{array}$ & $\begin{array}{l}\text { is article: } \\
\text { or KB, Kidd M, } \\
\text { I useful are } \\
\text { in blunt } \\
\text { Is for } \\
\text { ography of the } \\
\text { fr J Rad. } \\
837 \text {. https:// } \\
2 \text { /sajr. }\end{array}$ \\
\hline $\begin{array}{l}\text { Copyright: } \\
\text { (C) 2020. The A } \\
\text { Licensee: AOS } \\
\text { is licensed unc } \\
\text { Creative Com } \\
\text { Attribution Lic }\end{array}$ & $\begin{array}{l}\text { uthors. } \\
\text { IS. This work } \\
\text { ler the } \\
\text { nons } \\
\text { ense. }\end{array}$ \\
\hline Read online: & \\
\hline 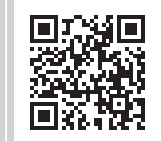 & $\begin{array}{l}\text { Scan this QR } \\
\text { code with your } \\
\text { smart phone or } \\
\text { mobile device } \\
\text { to read online. }\end{array}$ \\
\hline
\end{tabular}

Background: The relevance of clinical data included in blunt trauma referrals for abdominal computed tomography (CT) is not known.

Objectives: To analyse the clinical details provided on free-text request forms for abdominal CT following blunt trauma and assess their association with imaging evidence of intraabdominal injury.

Method: A single-institution, retrospective study of abdominal CT scans was performed for blunt trauma between 01 January and 31 March 2018. Computed tomography request forms were reviewed with their corresponding CT images. Clinical details provided and scan findings were captured systematically. The relationship between individual clinical features and CT evidence of abdominal injury was tested using one-way cross tabulation and Fisher's exact test.

Results: One hundred thirty-nine studies met inclusion criteria. A wide range of clinical details was communicated. Only clinical abdominal examination findings $(p=0.05)$, macroscopic haematuria $(p<0.01)$, pelvic fracture or hip dislocation $(p=0.04)$ and positive focused assessment with sonography in trauma $(p<0.01)$ demonstrated an associated trend with abdominal injury.

Conclusion: Key abdominal examination and basic imaging findings remain essential clinical details for the appropriate evaluation of CT abdomen requests in the setting of blunt trauma. Methods to improve consistent communication of relevant clinical details are likely to be of value.

Keywords: blunt trauma; tomography; X-ray computed; abdominal CT; justification; clinical content; electronic referral.

\section{Introduction}

Trauma remains a major global public health problem and is the leading cause of hospitalisation, long-term disability and death in persons aged less than 40 years. ${ }^{1}$ Blunt trauma accounts for the majority of injuries. ${ }^{2}$

Approximately $15 \%$ of patients admitted in level-1 trauma centres have abdominal injuries. ${ }^{3}$ Clinical evaluation of blunt abdominal trauma has low sensitivity and specificity for injured organs. In neurologically intact, blunt trauma patients, trauma surgeons miss almost half of all abdominal injuries prior to imaging. ${ }^{4}$ Furthermore, missed injuries are more frequent in severe trauma, whilst in patients with decreased level of consciousness, injuries may be occult. ${ }^{5}$ Computed tomography (CT) has thus emerged as a definitive investigation for blunt abdominal injuries. However, there are concerns about its overutilisation, thereby exposing patients to unnecessary ionising radiation and inflating healthcare costs. ${ }^{6,7}$

South Africa has no local guidelines informing patient selection for CT abdomen in the setting of blunt trauma. International studies in this domain so far have been confounded by wide disparity in study design and terminology. ${ }^{8,9,10,11}$ Nonetheless, most guidelines recommend whole-body CT for major blunt trauma in adult patients Injury Severity Score $>15.12,13,14,15$ However, the National Institute for Health and Care Excellence (NICE) in the UK acknowledges low-quality observational studies that inform such guidelines. Additionally, although various clinical decision tools have been developed in an attempt to identify patients at a very low risk of abdominal injury, and thus not warranting further investigation, uptake of such guidelines has been very limited. . $^{16,17,18}$ 
Justification is the decision-making process whereby the perceived benefits and potential risks of an examination are considered. Radiologists are responsible for the justification of medical exposure to ionising radiation, including traumarelated CT scans. ${ }^{19}$ To this end, referring clinicians are obliged to provide radiologists with sufficient clinical information to assess the merits of each investigation.

Many radiology departments utilise free-text referrals to convey information from clinician to radiologist. This communication is integral for optimising patient care and healthcare resources by ensuring that every scan is warranted, appropriately performed and reported.

The American College of Radiology stipulates that referrals should include relevant clinical information, a working diagnosis, pertinent signs and symptoms, as well as a specific clinical question. ${ }^{20}$ The Royal College of Radiologists suggests that clinical information might include medical symptoms or signs pointing to a particular diagnosis or range of diagnoses. The radiologist reporting the examination should understand the 'explicit and implied information' contained in the clinical details, appreciating their relevance and diagnostic importance when interpreting the imaging study. ${ }^{21}$ The quality of clinical detail on the referral should thus enhance both patient selection and the reporting of studies. ${ }^{22}$ However, a key challenge confronting the radiologist contemplating CT requests for trauma patients is that the value of any specific clinical detail provided in predicting abdominal injury is unknown to both referring clinician and radiologist.

Without insights into the association between request content and CT findings, the free text request is potentially arbitrary. Establishing a link between clinical request and CT findings would enhance the justification process.

We, therefore, aimed to describe the specific clinical details that clinicians elect to communicate and assess whether there is any association with imaging evidence of abdominal injury.

\section{Research methods and design}

This was a retrospective analysis of the free-text request forms and corresponding images of all abdominal CT scans performed for blunt trauma from 01 January 2018 through 31 March 2018 at Tygerberg Hospital (TBH). Tygerberg Hospital is a 1386-bed tertiary-level, public sector facility in Cape Town, South Africa. It is the main teaching hospital of the Faculty of Medicine and Health Sciences of Stellenbosch University and has a level-1 equivalent trauma unit, which manages approximately 24000 cases annually. Tygerberg Hospital has a digital, filmless and paperless imaging environment, in which all examinations are requested electronically. The electronic workflow requires formal approval of the radiologist for all imaging investigations except plain radiographs, and precludes scheduling of special examinations prior to the radiologist's justification.

A systematic search of institutional radiology information system (RIS) was undertaken for initial abdominal CT scans
TABLE 1: Criteria defining a computed tomography diagnosis of abdominal injury and/or extra-abdominal injury.

\begin{tabular}{ll}
\hline CT diagnosis of abdominal injury & CT diagnosis of extra-abdominal injury \\
\hline Intraperitoneal free fluid $\dagger$ & Lower rib fracture \\
\hline Intra- or retroperitoneal free air & Diaphragm injury \\
Solid organ injury $\$$ & Thoracolumbar spine injury \\
\hline Ureter or urinary bladder injury & Isolated transverse process fractures \\
Bowel or mesenteric injury & Pelvic or proximal femur fractures or hip dislocation \\
Vascular injury & -
\end{tabular}
Vascular injur

$\mathrm{CT}$, computed tomography.

$\dagger$ Excluded minimal free fluid in absence of other evidence of abdominal injury; $\downarrow$, Liver, spleen, pancreas, kidney or adrenal injury; $\S$. Excluded isolated transverse process fractures.

of all adult patients (aged $>18$ years) investigated for blunt trauma during the review period. Studies were excluded if CT scans were performed following laparotomy, as repeat scans, or without intravenous contrast.

All clinical data included on the free-text electronic CT requests were systematically captured on a customised Microsoft Excel spreadsheet and stratified by patient demographics, clinical history, vital signs and haemodynamic status, abdominal and extra-abdominal examination findings, side-room investigations, laboratory test results, and baseline imaging features.

Definitions for positive abdominal and extra-abdominal examination findings were adapted from previous studies evaluating abdominal examination in blunt trauma. ${ }^{5,23} \mathrm{~A}$ positive abdominal examination included any specification of abdominal bruising or abrasions, abdominal pain, tenderness or distension, low back pain, macroscopic haematuria or bruised chest. A positive extra-abdominal examination included specification of suspected injury to the head, cervical spine, thorax, thoracolumbar spine, pelvic fracture or hip dislocation, or long bone fractures.

All CT scans were re-reported by the lead investigator (K.B.C.), a radiology registrar with 4 years of experience. Any discrepancies with the final radiology report were resolved by consensus in consultation with the same consultant radiologist who authorised the report. Computed tomography findings were stratified by abdominal organ, utilising the respective American Association for the Surgery of Trauma (AAST) classifications for solid organ injury. ${ }^{24}$ Extra-abdominal injuries were also captured (Table 1).

Relationships between variables on electronic request and CT diagnosis of abdominal injury were tested using cross tabulation and Fisher's exact test. Age differences were tested using one-way analysis of variance.

\section{Ethical consideration}

This was a retrospective study. Confidentiality was maintained at all times. The study was approved by the Stellenbosch Research Ethics Committee (Reference No. S18/07/142).

\section{Results}

One hundred thirty-nine patients $(n=139)$, with a mean age of 37 years (male: $n=110,79 \%$ ) were included in the analysis. 
In most patients $(n=86 ; 62 \%)$, the abdominal study was performed in conjunction with CT of other anatomical regions; in 28 patients $(20 \%)$ it was a part of whole-body CT and in $25(18 \%)$, CT was limited to the abdomen.

\section{Request form content}

Request form information is presented in Table 2. A total of 976 diverse free-text clinical details were provided on 139 request forms, reflecting an average of seven details per referral. All referrals $(n=139,100 \%)$ provided at least one abdominal $(n=95,68 \%)$ or extra-abdominal $(n=127,91 \%)$ clinical examination finding; 134 (96\%) included a detail on clinical history; 70 (50\%) reported side-room investigations; 45 (32\%) reported baseline imaging results and $14(10 \%)$ gave laboratory findings. No referral reflected detail in all categories.

Mechanism of injury $(n=132 ; 95 \%)$ was specified in the majority of cases, the Glasgow Coma Scale or mental status ( $n=97 ; 70 \%$ ) was reported in just over two-thirds of patients, and microscopic haematuria $(n=69 ; 50 \%)$ in approximately half the referrals. Of note, abdominal examination was deemed 'unreliable' in almost one-fifth of cases $(n=27 ; 19 \%)$ because of the patient's decreased level of consciousness. Almost one-quarter $(n=33 ; 24 \%)$ recorded vital signs or haemodynamic status, and less than one-fifth referred to focused assessment with sonography in trauma (FAST; $n=24 ; 17 \%)$.

\section{Computed tomography findings}

Abdominal injury was diagnosed in approximately onequarter of patients $(n=36 ; 26 \%)$, most of whom had solid organ injury $(n=34 ; 24 \%)$. There was no AAST grade 5 injury. There were six grade $4(4 \%)$ and $35(25 \%)$ grade 3 or less AAST injuries documented. Grade 4 injuries involved the liver $(n=3)$, spleen $(n=2)$ and kidney $(n=1)$, all having positive abdominal examinations. The five non-solid organ injuries involved the bladder $(n=2)$, abdominal vasculature $(n=2)$ and bowel $(n=1)$ - all were associated with solid organ injury and had positive abdominal examination, X-ray or FAST findings (Table 3).

\section{Association between electronic request and abdominal injury}

The association between request form details and CT evidence of abdominal injury is summarised in Table 4 .

Referral details trending towards association with abdominal injury were positive abdominal examination $(p=0.05)$, macroscopic haematuria $(p<0.01)$, pelvic fracture or hip dislocation $(p=0.04)$ and positive FAST $(p<0.01)$. Negative abdominal examination, absence of macroscopic haematuria and negative FAST were negatively associated with abdominal injury.

Thus, only 186/976 (19\%) of all clinical details on request forms were associated with abdominal injury.
TABLE 2: Frequency of request form detail $(N=139)$.

\begin{tabular}{|c|c|c|c|}
\hline Section & Item & Frequency & $\%$ \\
\hline \multirow[t]{3}{*}{ History } & Any entry & 134 & 96 \\
\hline & Total entries & 171 & - \\
\hline & Mechanism of injury & 132 & 95 \\
\hline \multirow{2}{*}{$\begin{array}{l}\text { Vital signs or } \\
\text { haemodynamic status }\end{array}$} & Any entry & 33 & 24 \\
\hline & Total entries & 35 & - \\
\hline \multirow[t]{3}{*}{ Abdominal examination } & Any entry & 95 & 68 \\
\hline & Total entries & 209 & - \\
\hline & Unreliable & 27 & 19 \\
\hline \multirow{3}{*}{$\begin{array}{l}\text { Extra-abdominal } \\
\text { examination }\end{array}$} & Any entry & 127 & 91 \\
\hline & Total entries & 324 & - \\
\hline & GCS/mental statusì & 97 & 70 \\
\hline \multirow[t]{2}{*}{ Side-rooms } & Any entry & 70 & 50 \\
\hline & Total entries & 119 & - \\
\hline \multirow[t]{2}{*}{ Lab tests } & Any entry & 14 & 10 \\
\hline & Total entries & 14 & - \\
\hline \multirow[t]{3}{*}{ Imaging } & Any entry & 45 & 32 \\
\hline & Total entries & 104 & - \\
\hline & FAST $\S$ & 24 & 17 \\
\hline
\end{tabular}

GCS, Glasgow Coma Scale; FAST, focused assessment with sonography in trauma.

$\dagger$, Any mention of GCS or mental status, whether quantified or not; $\ddagger$, Urinalysis was 'pending' in one request form; $\S$, FAST was 'unavailable' in four requests forms.

TABLE 3: Computed tomography abdomen findings.

\begin{tabular}{|c|c|c|c|c|}
\hline Organ injured & Subcategory & Grading & $\begin{array}{c}\text { Frequency } \\
(N=139)\end{array}$ & $\%$ \\
\hline Any abdominal injury $\dagger$ & - & - & 36 & 26 \\
\hline Free fluid & - & - & 30 & 22 \\
\hline Free air & - & - & 3 & 2 \\
\hline \multirow[t]{19}{*}{ Solid organ } & - & - & 34 & 24 \\
\hline & Liver & - & 25 & 20 \\
\hline & & Liver, grade 5 & 0 & \\
\hline & & Liver, grade 4 & 3 & 2 \\
\hline & & Liver, grade 3 & 10 & 7 \\
\hline & & Liver, grade 2 & 9 & 6 \\
\hline & & Liver, grade 1 & 3 & 2 \\
\hline & Spleen & - & 8 & 6 \\
\hline & & Spleen, grade 5 & 0 & \\
\hline & & Spleen, grade 4 & 2 & 1 \\
\hline & & Spleen, grade 3 & 3 & 2 \\
\hline & & Spleen, grade 2 & 1 & 1 \\
\hline & & Spleen, grade 1 & 2 & 1 \\
\hline & Kidney & - & 8 & 6 \\
\hline & & Kidney, grade 5 & 0 & \\
\hline & & Kidney, grade 4 & 1 & 1 \\
\hline & & Kidney, grade 3 & 5 & 4 \\
\hline & & Kidney, grade 2 & 2 & 1 \\
\hline & & Kidney, grade 1 & 0 & \\
\hline \multirow[t]{6}{*}{ Non-solid organ } & Ureter & - & 0 & 0 \\
\hline & Bladder & - & 2 & 1 \\
\hline & Bowel & - & 1 & 1 \\
\hline & Mesenteric & - & 0 & 0 \\
\hline & Vascular & - & 2 & 1 \\
\hline & - & $\begin{array}{l}\text { Vascular contrast } \\
\text { extravasation }\end{array}$ & 1 & 1 \\
\hline
\end{tabular}

$\dagger$, Total patients with any single injury or a combination of injuries.

\section{Discussion}

There is a wealth of literature investigating the value of various signs and symptoms, side-room tests and imaging investigations in predicting the probability of abdominal injury. 
TABLE4: Association between request form detail and computed tomography evidence of abdominal injury.

\begin{tabular}{|c|c|c|c|c|c|c|c|c|}
\hline \multirow[t]{2}{*}{ Section } & \multirow[t]{2}{*}{ Item } & \multicolumn{2}{|c|}{ Frequency } & \multirow[t]{2}{*}{$\%$} & \multicolumn{2}{|c|}{ Abdominal injury present } & \multirow[t]{2}{*}{$\%$} & \multirow[t]{2}{*}{$p^{*}$} \\
\hline & & $n$ & $N$ & & $n$ & $N$ & & \\
\hline \multirow[t]{4}{*}{ History } & Mechanism & 132 & 139 & 95 & 32 & 132 & 24 & 0.08 \\
\hline & Vehicle accidents (MVA \& PVA) & 85 & 132 & 64 & 23 & 85 & 27 & - \\
\hline & Assault & 22 & 132 & 17 & 7 & 22 & 32 & - \\
\hline & Other & 25 & 132 & 19 & 2 & 25 & 8 & - \\
\hline \multirow[t]{20}{*}{ Examination } & Vital signs $\dagger$ & 28 & 139 & 20 & 6 & 28 & 21 & 0.06 \\
\hline & Normal & 10 & 28 & 36 & 0 & 10 & 0 & - \\
\hline & Abnormal & 18 & 28 & 64 & 6 & 18 & 33 & - \\
\hline & Abdominal exam $\S$ & 75 & 139 & 54 & 26 & 75 & 35 & 0.05 \\
\hline & Positive & 66 & 75 & 88 & 23 & 66 & 35 & - \\
\hline & Negative & 9 & 75 & 12 & 0 & 9 & 0 & - \\
\hline & Macroscopic haematuria & 66 & 139 & 47 & 23 & 66 & 35 & $<0.01$ \\
\hline & Present & 17 & 66 & 26 & 11 & 17 & 65 & - \\
\hline & Absent & 49 & 66 & 74 & 12 & 49 & 24 & - \\
\hline & $14-15$ & 28 & 92 & 30 & 6 & 28 & 21 & - \\
\hline & $\leq 13$ & 64 & 92 & 70 & 17 & 64 & 27 & - \\
\hline & Extra-abdominal injury $\mid \uparrow$ & 117 & 139 & 84 & 52 & 117 & 44 & - \\
\hline & Head & 77 & 117 & 66 & 19 & 77 & 25 & 0.66 \\
\hline & Facial & 17 & 117 & 15 & 4 & 17 & 24 & 1 \\
\hline & Cervical spine & 7 & 117 & 6 & 2 & 7 & 29 & 1 \\
\hline & Thoracic & 26 & 117 & 22 & 8 & 26 & 31 & 0.62 \\
\hline & Dorsal spine & 9 & 117 & 8 & 1 & 9 & 11 & 0.44 \\
\hline & Lumbar spine & 7 & 117 & 6 & 0 & 7 & 0 & 0.19 \\
\hline & Pelvic fracture or hip dislocation & 25 & 117 & 21 & 11 & 25 & 44 & 0.04 \\
\hline & Long bone fracture & 17 & 117 & 15 & 7 & 17 & 41 & 0.15 \\
\hline \multirow[t]{3}{*}{ Side-rooms } & Microhaematuria & 69 & 139 & 50 & 14 & 69 & 20 & 0.58 \\
\hline & Present & 64 & 69 & 93 & 14 & 64 & 22 & - \\
\hline & Absent & 5 & 69 & 7 & 0 & 5 & 0 & - \\
\hline Imaging & FAST & 20 & 139 & 14 & 7 & 20 & 35 & $<0.01$ \\
\hline
\end{tabular}

MVA, motor vehicle accident; PVA, pedestrian vehicle accident; GCS, Glasgow Coma Scale; FAST, focused assessment with sonography in trauma.

*, Fisher's exact test; $\dagger$, Analysis includes all cases classifiable as normal or abnormal; $\S$, Analysis includes all cases classifiable as positive or negative; $\uparrow$, Analysis includes all cases where GCS was quantified; $\uparrow \uparrow$, Analysis excludes GCS/mental status, intoxication status and intubation status.

In a systematic review, Nishijima et al. $^{5}$ concluded that bedside ultrasonography had the highest accuracy, that a combination of clinical findings were likely to be most useful to select patients who were unlikely to benefit from further evaluation, but that the ideal combination was yet to be determined. To our knowledge, this is the first study to investigate whether these are reliably reflected in the free-text request form.

Our study had a number of key findings. Firstly, only 19\% of clinical details reflected on free-text referrals at our institution were associated with imaging evidence of abdominal injury. This calls into question the role of such referrals and suggests there is room for substantial improvement in this domain.

Secondly, we reaffirmed the pivotal role of meticulous clinical abdominal examination in the setting of blunt trauma. Of note, only $54 \%$ of patients undergoing abdominal CT had mention of abdominal examination findings interpretable as positive or negative. A potential explanation for this less than comprehensive documentation of abdominal findings is that guideline-driven imaging protocols frequently recommend abdominal CT to rule out occult abdominal injuries in patients with head injuries, citing that clinical abdominal examination is likely to be unreliable in this setting. This could lead less experienced clinicians to assume that abdominal examination findings are of limited value. Our study suggests that abdominal examination findings form a relevant component of referral and should be provided, whether positive or negative. A normal abdominal examination is predictive of the absence of abdominal injury.

Thirdly, our study suggests that FAST could play a role in the reduction of abdominal CT utilisation in the blunt trauma setting, in line with findings of Sheng et al..$^{25}$ Efforts should be made to expand the use of FAST. This would involve developing appropriate skills amongst clinicians. Focused assessment with sonography in trauma training programmes are increasingly available, and ultrasound machines are becoming more affordable and portable. Any unit with a CT scanner should be equipped with basic ultrasound equipment.

We found no evidence to support the provision of qualitative or quantitative information about microscopic haematuria, consistent with studies demonstrating its low value. ${ }^{26,27}$ The relatively high frequency $(50 \%)$ of documentation on electronic requests could be because of the speed and ease of the test during the trauma admission procedure. Clinicians 
equivocating about the need of CT could include microscopic haematuria as a further motivation for requesting $\mathrm{CT}$, particularly in the absence of other compelling indications. Our findings suggest that CT abdomen for isolated microscopic haematuria, in the absence of any other finding, is not justified.

Although free text electronic requests permit clinical information to be communicated without constraint, a major limitation is that provision of relevant content remains voluntary. Methods of improving the consistent provision of relevant clinical content on imaging requests are likely to strengthen the evidence base of this information and facilitate an optimal justification process. There may be a role of a drop-down menu-style electronic request, thus obliging referring clinicians to provide relevant information and restricting the communication of irrelevant information.

There are limitations in the statistical analysis of free text referrals. The retrospective design meant that parameters were not specified in every case, thereby preventing determination of their diagnostic sensitivities and specificities. Prospective studies are needed to analyse systematically the diagnostic value of various contents on electronic request. Furthermore, we only conducted a univariate analysis. Given the complex clinical variables in trauma, a multivariate analysis controlling for confounding variables would represent a superior analysis. The capture of data pertaining to imaging tests performed prior to CT was limited in that it was occasionally impossible to determine whether findings had been diagnosed on examination or on imaging tests.

The strengths of the study included the availability of comprehensive RIS data and ability to enrol consecutive patients with little exclusion.

\section{Conclusion}

Key abdominal examination and basic imaging findings remain essential clinical details for the appropriate evaluation of CT abdomen requests in the setting of blunt trauma. Requests specifying a positive abdominal examination, macroscopic haematuria, pelvic fracture or hip dislocation, or positive FAST are associated with CT evidence of abdominal injury. Methods to improve consistent communication of relevant clinical details are likely to be of value.

\section{Acknowledgements}

\section{Competing interests}

The authors have declared that no competing interests exist.

\section{Authors' contributions}

K.B.B-C. was the guarantor of integrity of the entire study. K.B.B-C. and R.D.P. were responsible for study concepts and design, and literature research. M.K. was responsible for experimental studies or data analysis, and statistical analysis.
K.B.B-C. prepared the manuscript, and K.B.B-C. and R.D.P. contributed towards manuscript editing.

\section{Funding information}

This research received no specific grant from any funding agency in public, commercial or not-for-profit sectors.

\section{Data availability statement}

Raw data were generated at Tygerberg Hospital. Derived data supporting the findings of this study are available from the corresponding author (K.B.B-C.) upon request.

\section{Disclaimer}

The views and opinions expressed in this article are those of the authors and do not necessarily reflect the official policy or position of any affiliated agency of the authors.

\section{References}

1. Rhee $P$, Joseph $B$, Pandit $V$, et al. Increasing trauma deaths in the United States. Ann Surg. 2014;260(1):13-21. https://doi.org/10.1097/SLA.0000000000000600

2. Isenhour JL, Marx J. Advances in abdominal trauma. Emerg Med Clin North Am. 2007;25(3):713-733. https://doi.org/10.1016/j.emc.2007.06.002

3. Arumugam S, Al-Hassani A, El-Menyar A, et al. Frequency, causes and pattern of abdominal trauma: A 4-year descriptive analysis. J Emerg Trauma Shock. 2015;8(4):193-198. https://doi.org/10.4103/0974-2700.166590

4. Beal AL, Ahrendt MN, Irwin ED, et al. Prediction of blunt traumatic injuries and hospital admission based on history and physical exam. World J Emerg Surg. 2016;11(46):1-6. https://doi.org/10.1186/s13017-016-0099-9

5. Nishijima DK, Simel DL, Wisner DH, Holmes JF. Does this adult patient have a blunt intra-abdominal injury? JAMA. 2012;307(14):1517-1527. https://doi.org/10.1001/ jama.2012.422

6. Smith-Bindman R, Lipson J, Marcus R, et al. Radiation dose associated with common computed tomography examinations and the associated lifetime attributable risk of cancer. Arch Intern Med. 2009;169(22):2078-2086. https:// doi.org/10.1001/archinternmed.2009.427

7. Gardner RL, Sarkar U, Maselli JH, Gonzales R. Factors associated with longer ED lengths of stay. Am J Emerg Med. 2007;25(6):643-650. https://doi.org/10.1016/j. ajem.2006.11.037

8. Treskes K, Saltzherr T, Luitse J, Beenen L, Goslings J. Indications for total-body computed tomography in blunt trauma patients: A systematic review. Eur J Trauma Emerg Surg. 2017;43(1):35-42. https://doi.org/10.1007/s00068-016-0711-4

9. Sampson MA, Colquhoun KBM, Hennessy NLM. Computed tomography whole body imaging in multi-trauma: 7 years experience. Clin Radiol. 2006;61(4):365369. https://doi.org/10.1007/s00068-016-0711-4

10. Milia DJ, Brasel K. Current use of CT in the evaluation and management of injured patients. Surg Clin North Am. 2011;91(1):233-248. https://doi.org/10.1016/j suc.2010.10.018

11. Millo NZ, Plewes C, Rowe BH, Low G. Appropriateness of CT of the chest, abdomen, and pelvis in motorized blunt force trauma patients without signs of significant injury. Am J Roentgenol. 2011;197(6):1393-1398. https://doi.org/10.2214/AJR.11.6536

12. Glen J, Constanti M, Brohi K. Assessment and initial management of major trauma: Summary of NICE guidance. BMJ. 2016;353(3051):i3051. https://doi. org/10.1136/bmj.i3051

13. Shyu J, Khurana B, Soto J, et al. ACR appropriateness criteria ${ }^{\circ}$ Major blunt trauma [homepage on the Internet]. 2019 [cited 2019 Dec 15]. Available from: https:// acsearch.acr.org/docs/3102405/Narrative/

14. The Royal College of Radiologists. Standards of practice and guidance for trauma radiology in severely injured patients [homepage on the Internet]. 2nd ed. London: The Royal College of Radiologists; 2015 [cited 2017 Oct 5]. Available from: www.rcr.ac.uk

15. Baker SP, O'Neill B, Haddon Jr. W, Long WB. The injury severity score: A method for describing patients with multiple injuries and evaluating emergency care. J Trauma. 1974;14(3):187-196. https://doi.org/10.1097/00005373-197403000-00001

16. Kendall J, Kestler A, Whitaker K, Adkisson M-M, Haukoos J. Blunt abdominal trauma patients are at very low risk for intra-abdominal injury after emergency department observation. West J Emerg Med. 2011;12(4):496-504. https://doi. org/10.5811/westjem.2010.11.2016

17. Holmes JF, Wisner DH, McGahan JP, Mower WR, Kuppermann N. Clinical prediction rules for identifying adults at very low risk for intra-abdominal injuries after blunt trauma. Ann Emerg Med. 2009;54(4):575-584. https://doi.org/10.1016/j. annemergmed.2009.04.007 
18. Corwin MT, Sheen L, Kuramoto A, Lamba R, Parthasarathy S, Holmes JF. Utilization of a clinical prediction rule for abdominal-pelvic CT scans in patients with blunt
abdominal trauma. Emerg Radiol. 2014;21(6):571-576. https://doi.org/10.1007/ s10140-014-1233-1

19. lonising radiation (medical exposure) regulations 2000 [homepage on the Internet]. London: The Stationery Office; 2000 [cited 2020 Mar 8]. Available from: http://www.legislation.gov.uk/uksi/2000/1059/pdfs/uksi_20001059_en.pdf

20. Sherry C, Adams M, Berlin L, editors. ACR practice parameter for communication of diagnostic imaging findings, Revised 2014 (Resolution 11). In: Practice parameters \& technical standards [homepage on the Internet]. American College of Radiology; 2017 [cited 2018 Apr 15]. Available from: https://www.acr.org/-/ media/ACR/Files/Practice-Parameters/CommunicationDiag.pdf

21. The Royal College of Radiologists. Standards for interpretation and reporting of imaging investigations [homepage on the Internet]. 2nd ed. London: The Roya College of Radiologists; 2018 [cited 2019 Dec 10]. Available from: www.rcr.ac.uk

22. Leslie A, Jones AJ, Goddard PR. The influence of clinical information on the reporting of CT by radiologists. Br J Radiol. 2000;73(874):1052-1055. https://doi. org/10.1259/bjr.73.874.11271897
23. Deunk J, Brink M, Dekker HM, et al. Routine versus selective computed tomography of the abdomen, pelvis, and lumbar spine in blunt trauma: A tomography of the abdomen, pelvis, and lumbar spine in blunt trauma: A
prospective evaluation. I Trauma. 2009;66(4):1108-1117. https://doi. org/10.1097/TA.0b013e31817e55c3

24. Kozar RA, Crandall M, Shanmuganathan K, et al. Organ injury scaling 2018 update: Spleen, liver, and kidney. J Trauma Acute Care Surg. 2018;85(6):1119-1122. https://doi.org/10.1097/TA.0000000000002058

25. Sheng AY, Dalziel P, Liteplo AS, Fagenholz P, Noble VE. Focused assessment with sonography in trauma and abdominal computed tomography utilization in adult trauma patients: Trends over the last decade. Emerg Med Int. 2013;2013:1-7. https://doi.org/10.1155/2013/678380

26. Sabzghabaei A, Shojaee M, Safari S, Hatamabadi HR, Shirvani R. The accuracy of urinalysis in predicting intra-abdominal injury following blunt traumas. Emergency (Tehran, Iran). 2016;4(1):11-15.

27. Olthof DC, Joosse P, Van Der Vlies CH, De Reijke TM, Goslings JC. Routine urinalysis in patients with a blunt abdominal trauma mechanism is not valuable to detect urogenital injury. Emerg Med J. 2015;32(2):119-123. https://doi.org/10.1136/ emermed-2013-202651 